\title{
THE FEE TENDERING AND SERVICE QUALITY ISSUE REVISITED
}

\author{
Michael Hoxley
}

School of Architecture, Design and the Built Environment, Nottingham Trent University, Burton Street, Nottingham NG1 4BU, UK (mike.hoxley@ntu.ac.uk)

\begin{abstract}
Purpose - It is a little over twenty years since mandatory fee scales were abolished by UK professional bodies. During this period fee levels have fluctuated with economic demand, and new procurement strategies such as partnering have been developed, but there is still a widespread view in industry, that fee levels are too low. This view is shared by many professionals, and perhaps more surprisingly by clients, even in the current construction and property boom. The research reported in this paper investigates the link between competitive fee tendering and clients' perceptions of service quality in the UK Property Industry. The main hypothesis is that there is a causal relationship between service quality and the method of appointment of the professional.

Design/methodology/approach - The research involved unstructured interviews with clients and professionals and a postal questionnaire study of one hundred and thirty three UK based clients. The questionnaire study was a repeat of a similar survey conducted eight years previously in very different economic conditions. The public and private sector clients each assessed the service quality received from a professional using a measurement scale developed from the generic service industry instrument SERVQUAL. The scale is used to test the main hypothesis and four sub-hypotheses. There were twice as many private sector clients completing the questionnaires as there were public sector clients and the largest group of professionals assessed were General Practice Chartered Surveyors.

Findings - The results of the recent study are similar to the earlier one (in that evidence of the predicted relationship is not provided by the data) but there are some interesting differences in the results of both studies - fee tendering has declined in popularity, direct appointment has increased, but less than $5 \%$ of the commissions were let on a partnered basis.

Practical implications - Property managers and other professionals may wish to make use of the service quality measurement scale in order assess the service they provide to clients. Originality/value - The research provides confirmation that clients do not perceive that a lower standard of service quality is provided for fee tendered commissions. It also extends the already substantial body of research based upon the SERVQUAL measurement technique.

Keywords - property, construction, fee tendering, professionals, service quality.

Paper type - Research paper
\end{abstract}

\section{INTRODUCTION}

There is hardly anything in the world today that someone cannot make just a little worse and sell a little cheaper and people who buy on price alone are this man's lawful prey. It is unwise to pay too much, but it is also unwise to pay too little. When you pay too much, you lose a little money, that is all. When you pay too little, you sometimes lose everything because the thing you bought is incapable of doing the thing you bought it to do.... If you deal with the lowest bidder it is well to add something for the risk you run. And if you do that you will have enough to pay for something better.

This quotation is often referred to as ‘Ruskin’s Law of Business’ after John Ruskin

(1819-1900) but there is actually no evidence that the great man said or wrote it and 
its exact source has been lost (Landow, 2000; FuG Elektronik, 2005). However its sentiments very clearly sum up those held by UK property and construction professionals in the mid-1990s when the worst recession for fifty years was causing fee levels to fall to unprecedented levels (Morgan 1993). It was then only a decade since mandatory fee scales had been abolished and many professionals were struggling to survive. It was at this time that the author collected data for his Doctoral research which was funded by the RICS Education Trust (Hoxley, 2000b). One of the recommendations of that earlier research was that similar data should be collected under improved economic conditions (Hoxley 1998: 182) and the UK certainly has those in the middle of this opening decade of the twenty-first century. Fuelled by the longest period of sustained economic growth since 1700 (Brown 2005) and substantial Government spending, the order books of both contractors and professionals are full. The repeat data collection was funded by the author's previous institution (which has recently changed its name to incorporate that of Ruskin their founder). As with the original study, data was collected by postal questionnaire but initially unstructured interviews were carried out with industry experts to see whether fee tendering was still an issue.

\section{Current fee levels}

One might have expected fee levels to have risen during a period of high demand but views expressed by the interviewees suggest that this may not be the case. The head of building procurement for a public limited company wholly owned by the UK government expressed the following view: "I wish professionals would tender higher. I know they cannot possibly provide the service we require for the fees they are quoting”. A Regional Director of one of the UK’s largest Quantity Surveying 
practices said “Things are still tough out there - we are having to submit highly competitive fee tenders”. So what has changed? It was time to revisit the literature.

\section{Changes in professional services}

There has been a significant trend away from traditional procurement to design and build for large contracts in the UK (RICS 2003). In a study of over 1,500 construction projects, BCIS (2001) reported that the mean professional fee was just over $9 \%$ of the construction cost. However the average fee paid on design and build projects was $5.67 \%$, while the fee for traditionally procured projects was $10.33 \%$. Of course the level of input from professionals providing a service to contracting organisations is likely to be substantially less than that provided to a client traditionally procuring construction. One of the conclusions of the author's earlier study was that since fee levels had fallen and clients did not perceive any decline in service quality, professional firms must have become more efficient (Hoxley 2000b). This trend seems to have continued. In another study (CIC 2003), data collected in 2001/02 were compared with that collected in 1995/96 (the author's original data were collected in 1996). The CIC study reported that per capita fee income per professional had increased 19\% in real terms between 1996 and 2002 (CIC 2003: 48). There were interesting changes in the structure of professional organisations revealed by the CIC study. The proportion of work undertaken by multidisciplinary firms and 'no dominant service providers' had increased significantly and large firms now dominate the market. 46\% of firms in the 2001/02 survey described themselves as being 'multidisciplinary’ (CIC 2003: 54). In total 23,500 professional firms earned $£ 12.3$ billion on projects in the UK and only $3 \%$ of firms generated $60 \%$ of UK fee income (CIC 2003: 1). 


\section{Changes in procurement of professional services}

Of particular relevance to this research are the methods of procurement reported by the CIC study. $17 \%$ of all work was won through partnering (compared with $9 \%$ in 1995/96). Negotiation had fallen from 56\% to 39\% but competition had increased from $32 \%$ to $41 \%$. There were however interesting differences between the professions. Surveying firms generated 11\% of fee income in the sector in 2001/2002 yet employed $17 \%$ of all staff. Engineers earned more per capita than surveyors but in 1996 the reverse was true. Surveyors gained $77 \%$ of their instructions through competition while the equivalent figure for engineers was only 41\%. In the 1996 study engineers were the professionals that had the highest percentage of competitively procured commissions.

These findings were mirrored in research carried out a year later by the KPI Consortium (2004) which surveyed 376 consultants and reported on the number of new commissions arising from direct negotiations, as shown in Table 1. Thus engineers have been much better than the other professionals in moving away from fee tendered commissions.

Table 1: New commissions arising from direct negotiations (KPI Consortium 2004)

\begin{tabular}{|c|c|c|c|c|}
\hline \multirow[t]{2}{*}{ Negotiated Commissions } & \multicolumn{4}{|c|}{ Projects Completed to end 2003} \\
\hline & All Consultants & Architects & Surveyors & Engineers \\
\hline $\begin{array}{l}\% \text { of respondents who indicated that } \\
\text { the number of directly negotiated } \\
\text { commissions was equal to or greater } \\
\text { than the number of successful bids }\end{array}$ & $42 \%$ & $38 \%$ & $36 \%$ & $63 \%$ \\
\hline
\end{tabular}

In the public sector, compulsory competitive fee tendering (DOE 1994)) has given way to Best Value (DOE 1997) which has been implemented through framework 
agreements. The author interviewed a Principal Building Economist of a County Council. who explained in detail their recent experience of appointing consultants. Twenty multidisciplinary firms tendered initially. The basis of the tender was an exemplar project and bids were weighted $60 / 40$ on quality/price. The 20 were reduced to 12 as a result of this initial exercise and then down to six as a result of visits to the consultants' offices, seeing current projects and taking up other clients' references. Following implementation of the framework agreement, all six consultants are invited to bid for every project and a quality statement must be prepared for each project. The quality score for each project is weighted 33\% for previous performance and 66\% for the project statement. The 60/40 quality/price weighting is applied to each project and the "lowest price frequently does not secure the commission". One consultant has submitted 30 bids and has not secured a single commission - "he just cannot get his quality statements right”. Typical fees for new-build are in the $11-12 \%$ range.

Both the review of recent literature and the unstructured interviews suggest that the issue of competitive fee tendering is as relevant during today's boom in activity as it was when data were originally collected. Indeed the relevance is further emphasised by advice given by the RICS to its Quantity Surveying (QS) members recently. In a web-based bulletin to its Construction Faculty members, the RICS (2004) reported that QSs were still being asked by clients for the fee scales upon which they based their charges. The advice concluded with a recommendation that appointment should be made on the basis of value rather than cost. The author's 1996 survey is summarised below. 


\section{THE 1996 STUDY}

The methodology for the original research was reported in Hoxley (2000a) and the results in Hoxley (2000b) but a concise summary follows. Several commentators in the mid-1990s were documenting the significant decline in the level of professional fees following the abolition of mandatory fee scales a decade earlier (e.g. Morgan 1993, Latham 1994 and Association of Consulting Engineers 1995). The concerns raised by these commentators about the impact of fee cutting upon levels of service led the author to state his main hypothesis - Clients' perceptions of service quality are lower for commissions let by competitive fee tendering than with other methods of appointment. There were also four sub-hypotheses which were concerned with the specification of the service, pre-selection of tenderers, the weighting given to ability, (CIRIA 1994) and with particularly competitive tenders. A service quality measurement scale was developed building upon Parasuraman et al.’s (1988 and 1991) twenty-two item scale, SERVQUAL. This scale measures quality across the five dimensions which they discovered (see Table 2).

Table 2: The SERVQUAL scale (Parasuraman at al, 1991)

\begin{tabular}{llc}
\hline \multicolumn{1}{c}{ Dimension } & \multicolumn{1}{c}{ Description } & $\begin{array}{c}\text { Number of } \\
\text { Items }\end{array}$ \\
\hline Tangibles & Physical facilities, equipment, and appearance of personnel & 4 \\
\hline Reliability & $\begin{array}{l}\text { Ability to perform the promised service dependably and } \\
\text { accurately }\end{array}$ & 5 \\
\hline Responsiveness & Willingness to help customers and provide prompt service & 4 \\
\hline Assurance & $\begin{array}{l}\text { Knowledge and courtesy of employees and their ability to } \\
\text { inspire trust and confidence }\end{array}$ & 4 \\
\hline Empathy & $\begin{array}{l}\text { Caring, individualised attention the firm provides its } \\
\text { customers }\end{array}$ & 5 \\
\hline
\end{tabular}

The SERVQUAL development work has been replicated by many researchers and several have recommended that the scale be adapted to suit each particular service setting. The author's original scale was developed by carrying out a comparison of the SERVQUAL study and three other studies, which were :- 
- a study of architectural service quality (Cravens et al., 1985);

- RESERV - a scale for assessing US real estate brokers (Nelson and Nelson, 1995); and

- a study of UK building surveying service quality (Hoxley, 1994).

The initial scale had 28 items upon which clients were requested to rate an anonymous consultant using a balanced Likert 7 point attitude scale. Two items which were included originally were dropped following purification of the scale because they were found to have insufficient correlation with other scale items and therefore with "service quality". The items were both concerned with the consultant's office - with its location and its appearance.

The scale was sent to 500 client organisations located throughout the UK and 244 clients responded (49\%) by anonymously assessing consultants. Over half of the clients who responded were local authorities. Nearly $60 \%$ of the professionals assessed were Chartered Surveyors (just over half of these were Quantity Surveyors), 19\% were Architects and 11\% were Engineers. An exploratory factor analysis (a statistical technique for condensing many variables into a few underlying factors, dimensions or constructs ) reduced the 26 scale items into four factors which the researcher named "What,” “When” "How” and "Who” (see Hoxley, 2000a for a full discussion of the loading of scale items onto each factor). The statistical analysis confirmed that the scale was both a reliable and valid instrument to measure service quality in a property and construction profession context. 
In addition to the assessment of the consultant, clients also answered questions that were associated with the five hypotheses. Thus they indicated the method by which the consultant was appointed (fee tendering, negotiation, direct appointment, other), and also answered questions relevant to the other hypotheses. In order to test each hypothesis, the service quality score was computed for each case. Means of this score (the dependent variable) were then computed and tabulated for each value of the independent variable associated with each hypothesis. Finally a one-way analysis of variance was computed to test the null hypothesis that there are no differences between these means.

The mean scores for the three main methods of appointment are indicated in Table 3 below.

Table 3 : Mean service quality scores by method of appointment (1996 study)

\begin{tabular}{lccc}
\hline Method of Appointment & $\mathrm{N}$ & $\%$ & Service Quality Score \\
\hline Negotiated & 72 & 29.9 & 4.31 \\
\hline Directly Appointed & 39 & 16.2 & 4.22 \\
\hline Competitive Fee Tendered & 127 & 52.7 & 4.17 \\
\hline
\end{tabular}

Thus over half of the consultants assessed were appointed by competitive fee tendering. The main hypothesis was however not supported by the data collected, in that although a lower score was recorded for those consultants appointed by competitive fee tendering, this result was not statistically significant. Similarly the hypotheses that service quality is lower when the fee bid is more competitive and higher when the service has been well specified, were not supported by the data. However the hypotheses that service quality is higher when care has been taken with 
the pre-selection of tenderers and when adequate weighting has been given to ability in the final selection process, were both supported by the analysis of the data.

\section{THE 2004 STUDY}

\section{Is SERVQUAL still relevant?}

In order to determine whether SERVQUAL is still a relevant methodology for measuring service quality the author once again returned to the literature. A keyword search of the Electronic Collections Online business and management database of journals produced the results illustrated in Figure 1. As can be seen, the use of SERVQUAL has increased since it was originally used by the author, peaking at 30 published papers in 2003. One of these (Finn and Kayande 2004) compares the use of the scale in 35 situations (including that in Hoxley 2000a) and focuses on the issue of scale modification. Finn and Kayande describe SERVQUAL as being 'influential' and conclude that initial adaptation (adding or deleting items depending on the context) has a greater impact on the resulting service quality score than refinement (deleting items because of poor correlation between items).

$<$ Insert Figure 1 about here $>$

The 26-item 1996 service quality scale was used as the basis of the data collection in the recent study. However an additional scale item (demonstrating good awareness of health and safety issues) was added. The CDM Regulations had come into force since the original survey and this factor is one of the Key Performance Indicators adopted by the KPI Consortium (2004). The only other changes made to the postal questionnaire were the inclusion of an additional method of appointment - 
'partnering' - and the option for the respondents to remain anonymous if they preferred. Copies of the final questionnaire are available upon request from the author and the scale item statements are indicated in Table 4 below. The questionnaire asked respondents to indicate how the service they received compared with their original expectation. A 7-point Likert scale was used with responses: 'very much better', ‘much better’, ‘better’, ‘same’, ‘worse’, ‘much worse’, or ‘very much worse’.

Table 4: 2004 service quality scale statements

\begin{tabular}{l}
\hline$X Y Z$ use up-to-date technology \\
\hline The staff of $X Y Z$ are always tidy in appearance \\
\hline The written and graphical output of $X Y Z$ is well presented \\
\hline$X Y Z$ 's size is appropriate for the services they perform for me \\
\hline$X Y Z$ 's solutions to problems are technically correct \\
\hline$X Y Z$ demonstrate good awareness of health and safety issues \\
\hline The design element of $X Y Z$ 's work shows creativity and capability \\
\hline$X Y Z$ provides its services at the time it promises to \\
\hline$X Y Z$ tells me when it will perform the service for me \\
\hline$X Y Z$ provides prompt service \\
\hline$X Y Z$ and its employees are always willing to help me \\
\hline$X Y Z$ and its employees are never too busy to respond to my requests \\
\hline Employees of $X Y Z$ are easily accessible to me \\
\hline I feel safe in my dealings with $X Y Z$ \\
\hline$X Y Z$ and its employees are always polite to me \\
\hline Employees of $X Y Z$ have the knowledge and competence to solve my problems \\
\hline$X Y Z$ and its employees have experience relevant to the service I require \\
\hline$X Y Z$ provide me with personal attention \\
\hline$X Y Z$ have only my best interests at heart \\
\hline$X Y Z$ understand my problems \\
\hline$I$ will benefit from a long term working relationship with XYZ \\
\hline$X Y Z$ and I have similar views about things that are important \\
\hline$X Y Z$ provide good cost control of projects \\
\hline The partners or directors of $X Y Z$ stay involved with my projects \\
\hline The site supervision of projects by XYZ is good \\
\hline The standard of verbal presentation by employees of $X Y Z$ is good \\
\hline$X Y Z$ and its employees understand my organisation \\
\hline
\end{tabular}

\section{Data collection}

The questionnaire was to be sent to client organisations and the RICS kindly provided a database of over 33,000 members who were located in one of the following employment categories: Director/Partner, Finance/Commercial, Building/Civil Engineering, Property Company, Central Government, Local Government or 
Education. From this sampling frame, 700 client-based individuals were identified and the questionnaire sent with a personally addressed covering letter and a stamped addressed envelope for return. One hundred and thirty three useable, completed questionnaires were returned. This response rate of $19 \%$ is low for a postal questionnaire and particularly low when compared with the $49 \%$ rate for the original, almost identical survey. A lower response rate had been anticipated (which is why 700 rather than 500 questionnaires were dispatched) because of 'survey fatigue' and much busier industrial activity. None the less the $19 \%$ response rate is disappointing. It is possible that clients do not see the issue of fee tendering to be as important as it was in 1996. Mention of the original research having been funded by the RICS Education Trust may have dissuaded some from participation (the RICS having recently caused some disaffection amongst its members by a substantial rise in subscription fees).

\section{Scale refinement}

All data analysis was carried out using SPSS and commenced with an exploratory factor analysis. This procedure is a statistical technique for condensing many variables into a few underlying factors, dimensions or constructs and commenced with a study of the correlation matrix of all twenty-seven of the scale variables. Hedderson (1991: 160) suggests that any variable whose correlations with the other variables are less than 0.4 in absolute terms should be excluded from the factor analysis. There was no variable that had a correlation of less than 0.4 with any of the other variables and thus no scale item was dropped (as indicated previously when analysing the 1996 data two variables had been dropped). 
Various measures of sampling accuracy were then computed to see whether the data were suitable for factor analysis. Bartlett's test of sphericity (which tests the hypothesis that the matrix is an identity matrix - that is all diagonal terms are 1 and all off-diagonal terms are 0) was 1808 with an associated significance level of 0.00000 . This suggests that the correlation matrix is unlikely to be an identity. Another indicator of the strength of the strength of the relationship among variables is the partial correlation coefficient. If variables share common factors, the partial correlation coefficients between pairs of variables should be small when the linear effects of the other variables are eliminated. The Kaiser-Meyer-Olkin measure is an index for comparing the magnitudes of the observed correlation coefficients to the magnitudes of the partial correlation coefficients and for the original correlation matrix was 0.93 . The negative of the partial correlation coefficient is called the antiimage correlation. The anti-image correlation matrix was computed and the smallest measure of sampling accuracy was 0.83 . All of these results suggest that the data collected is suitable for factor analysis (Norusis 1994: pp 50-53).

The twenty-seven variables of all 133 cases were then subjected to principalcomponents analysis which is a procedure that extracts the factors. The first principal component is the combination that accounts for the largest amount of variance in the sample. The second component (un-correlated with the first) explains the next largest amount of variance, and so on. This procedure extracted four factors which together accounted for $68 \%$ of the variance. The remaining twenty-two factors only explained the remaining $32 \%$ of the variance and this suggests that a four factor model fits the data collected (which is the same result as in 1996). 
The next stage in factor analysis is to rotate the factor matrix which is a procedure which attempts to identify the factors. After rotation the number of larger and smaller factor loadings increases, that is, variables are more highly correlated with single factors and more meaningful interpretation of the factors should become possible. The method of rotation selected was oblique which allows for correlations between factors (as opposed to orthogonal rotation which assumes no correlation between factors). It is unlikely that the factors are completely uncorrelated and "oblique rotations have often been found to yield substantively meaningful factors” (Norusis 1994: p71). Oblique rotation was used in the development of both the SERVQUAL and 1996 scales. Rotation is an iterative process and the data converged in 33 iterations.

Interpretation of the pattern matrix resulting from the rotation phase of the analysis did not suggest any clear identification of factors. Factor 1 had 21 of the 27 variables loaded on it (that is with a loading of $>0.25$ in absolute terms) and accounted for $54 \%$ of the variance. In addition 14 of the variables loaded on two or more factors. These results make a good case for arguing (as Babakus and Boller 1992, have done) that service quality is in fact a uni-dimensional construct.

\section{Assessing the reliability and validity of the service quality scale}

Any research instrument must be both reliable and valid (Churchill 1979). A test of reliability of the scale was carried out by computing the Cronbach Alpha coefficient. This was 0.97 which is slightly higher than the equivalent figure for the 1996 study and suggests that the scale has high reliability. In order to assess the scale’s validity, 
that is, “does it measure what it set out to measure?” an analysis of variance was carried out of the computed service quality scores and the answers to questions regarding the professional's overall quality of service and whether the client would recommend the professional to another organisation. This procedure aims to establish whether the scale score is capable of distinguishing between the responses to these other questions. For both questions the scale score was successful in distinguishing between groups and both analyses resulted in high F Ratios with very small associated probabilities. Figure 2 below is a plot of the mean service quality score for each response to the question about the overall quality of service. As will be seen the relationship is very nearly linear and these results confirm the validity of the scale.

$<$ Insert Figure 2 about here >

\section{Testing the hypotheses}

The main hypothesis was, as in 1996: Clients' perceptions of service quality are lower for commissions let by competitive fee tendering than with other methods of appointment and the sub-hypotheses were also identical. As before, in order to test the hypotheses, the service quality score for each case and means of this score (the dependent variable) were then computed and tabulated for each value of the independent variable associated with each hypothesis. Finally a one-way analysis of variance was computed to test the null hypothesis that there are no differences between these means.

\section{Results}

The distribution of the client organisations assessing professionals was very different from the earlier study. Whereas the public/private client ratio had been 75/25 previously, this time it was 32/68. This fact may further help to explain the poor 
response rate - in 1996 the public sector was being compelled to use fee tendering to appoint professionals and would have seen this research to be of great relevance. The distribution of professions assessed were however broadly similar - Surveyors 56\%, Architects 25\%, Engineers 8\% and Multi-disciplinary 5\%. This time General Practice Surveyors were the largest group of surveyors at 44\% (QS 23\% and Building Surveyors 16\%). It is necessary to be aware of the issue of 'non-response bias' when considering the results of the study. Less 'construction' professionals and more 'property' professionals were assessed in the recent study and it is clear from some comments made on the completed questionnaires (see 'Conclusion') that the subject of the repeat study had more resonance with property professionals than with those working in construction. As previously discussed, Surveyors have been less successful in moving away from fee tendering than some other professions (notably Engineers) and it is possible that the increased response rate from those in the property (rather than construction) professions is a reflection of this fact.

Table 5 below shows the mean service quality score for the 2004 and 1996 studies.

Table 5 : Mean service quality scores by method of appointment (2004 and 1996 studies)

\begin{tabular}{lcccccc}
\hline & \multicolumn{3}{c}{2004} & & \multicolumn{3}{c}{1996} \\
\hline Method of Appointment & $\mathrm{n}$ & $\%$ & SQ Score & $\mathrm{n}$ & $\%$ & SQ Score \\
& & & & & & \\
\hline Negotiation & 38 & 28.6 & 4.40 & 72 & 29.9 & 4.31 \\
\hline Direct Appointment & 38 & 30.1 & 4.33 & 39 & 16.2 & 4.22 \\
\hline Competitive Fee Tendering & 47 & 35.3 & 4.32 & 127 & 52.7 & 4.17 \\
\hline Partnering & 6 & 4.5 & 4.06 & - & - & - \\
\hline
\end{tabular}

It will be seen that fee tendering has declined in popularity, direct appointment has increased and less than $5 \%$ of these commissions were let on a partnered basis. All service quality scores have risen slightly and they are in the same rank order as eight 
years ago. Perhaps rather surprisingly the score for partnered projects is lower than for other methods of appointment (although of course a sample size of six is far too small to draw any useful conclusion from this result). The main hypothesis was once again not supported by the data as the ANOVA results are not significant (and in fact none of the other hypotheses is supported by the analysis).

\section{CONCLUSIONS}

The service quality measurement scale, based upon SERVQUAL and updated slightly during this research has been shown to be both a reliable and valid instrument for measuring the service quality of UK property and construction professionals. The scale has been used to test the stated fee tendering hypotheses in very different economic conditions to those that prevailed eight years ago. Once again the data collected from 133 clients has not supported the hypotheses. The latest study has therefore found no reason to believe that these surveyors, architects and engineers have provided an inferior service because they have tendered for their commissions. This is a testimony to their professionalism although, of course, providing a high quality service has its own rewards - repeat business, continued recommendation and referral and avoiding negligence claims, for example.

It is certainly the case that fee levels have fallen since the abolition of mandatory fee scales. Since the clients in both studies do not perceive any decline in service quality for fee tendered commissions then professional firms must have become more efficient in order to survive in these more competitive environments. Certainly the increased use of information technology has contributed to this enhanced efficiency 
but efficiency gains are also no doubt a key driver in the shift to more, and larger, multi-disciplinary professional organisations.

Property Managers and other professionals may wish to make use of the service quality measurement scale developed during this research in order to obtain client feedback on their own performance. Obtaining such feedback (and of course acting upon it) should ensure that they benefit from repeat business and recommendation and referral from satisfied clients and other professionals with whom they work.

Fee tendering does appear to be declining in importance, particularly in the public sector where there is no longer compulsion to impose it. Most of the clients participating in the latest research were from the private sector and one such client (the director of a property company) provided these comments in a letter accompanying his questionnaire:

.... there seems to be a presumption that all Companies should tender for professional services. While this may be applicable to Government or in some Public Companies for the sake of transparency I believe it to be entirely inappropriate within the environment within which Private Companies work. In my long experience I have found that this is a 'people business'. In those circumstances one tends to place work with other professionals with whom one has had the experience of working over a period of time and on several transactions. Where we have gone outside these relationships without recommendations (and sometimes with such recommendations) we have always encountered difficulties. For this reason a presumption to tender for the work for the purposes of reducing the fee element simply results, in my experience, in poor workmanship, poor communications and poor service.

This sounds rather like 'Ruskin’s law’ doesn’t it? In any event it certainly sounds like a recommendation to 'partner'! 


\section{REFERENCES}

Association of Consulting Engineers (1995) The Fisher Report: the role of the consulting engineer now and in the future: the client's perception. London: Association of Consulting Engineers.

Babakus, E and Boller, G W (1992) An empirical assessment of the SERVQUAL scale. Journal of Business Research, 24, 253-268.

BCIS (2001) Review of consultants' fees on construction projects. London: Building Cost Information Service Ltd.

Brown, G (2005) Budget Speech. $16^{\text {th }}$ March 2005, House of Commons, London.

Churchill, G A (1979) A paradigm for developing better measures of marketing constructs. Journal of Marketing Research, 16, 64-73.

CIC (2003) Survey of UK construction professional services 2001/2002. London: Construction Industry Council.

CIRIA (1994) Value by competition: a guide to the competitive procurement of consultancy services for construction. Special Publication 117. London: Construction Industry Research and Information Association.

Cravens, D W, Dielman T E and Kent, C (1985). Using buyers' perceptions of service quality to guide strategy development, in 1985 AMA Educators' Proceedings, Eds.R.F. Lusch, G.T. Ford, G.L. Frazier, R.D. Howell, C.A. Ingene, M. Reilly and R. Stampfl, Chicago: American Marketing Association, 297-301.

DOE (1994) Consultation paper on the implementation of compulsory competitive tendering for professional construction and property services. London: DOE.

DOE (1997) Better value for local authority services. News Release, 2 June 1997, London: DOE.

Finn, A and Kayande, U (2004) Scale modification: alternative approaches and their consequences. Journal of Retailing, 80(1), 37-52.

FuG Elektronik, 2005, About us, [WWW], http://www.fugelectronik.de/webdir/1/about our company.htm (last accessed 20/03/06).

Hedderson, J (1991) SPSS/PC+ made simple, Belmont, California, USA: Wadsworth Publishing Company.

Hoxley, M (1994) Assessment of building surveying service quality: process or outcome? RICS Research Series Paper, 1(8).

Hoxley, M (1998) The impact of competitive fee tendering on construction professional service quality, Unpublished PhD Thesis, Department of Surveying, University of Salford.

Hoxley, M (2000a) Measuring UK construction professional service quality: the what, how, when and who! International Journal of Quality and Reliability Management, 17(4/5), 511-526.

Hoxley, M (2000b) Are fee tendering and construction professional service quality mutually exclusive? Construction Management and Economics, 18(5), 599-605.

KPI Consortium (2004) Construction consultants’ KPIs, London: KPI Consortium.

Landow, G P (2000) A Ruskin Quotation? [WWW], http://www.victorianweb.org/authors/ruskin/quotation.html (last accessed 20/03/06). 
Latham, M (1994) Constructing the team: final report of the government/industry review of procurement and contractual arrangements in the UK construction industry. London: HMSO.

Morgan, D (1993) Fee cutting: have surveyors gone too low? CSW - The Property Week, 7 October 1993, London: The Builder Group, 28-29.

Nelson, S L and Nelson, T R (1995) RESERV: an instrument for measuring real estate brokerage quality. The Journal of Real Estate Research,10(1), 99-114.

Norusis, M J (1994) SPSS professional statistics 6.1, Chicago, USA: SPSS Inc.

Parasureman, A, Zeithaml, V A \& Berry, L L (1988) SERVQUAL: a multiple-item scale for measuring consumer perceptions of service quality. Journal of Retailing, 64(1), 1240.

Parasureman, A, Zeithaml, V A \& Berry, L L (1991) Refinement and reassessment of the SERVQUAL scale. Journal of Retailing, 67(4), 420-450.

RICS (2003) Contracts in use: a survey of building contracts in use 2001, London: RICS Construction Faculty.

RICS (2004) Calculating costs - why fee scales were dropped, [WWW], http://www.rics.org/NR/rdonlyres/80BCB669-0E06-499D-A4664B6E473C79F4/0/ConstructionBulletinAug04.pdf (last accessed 28/9/04). 


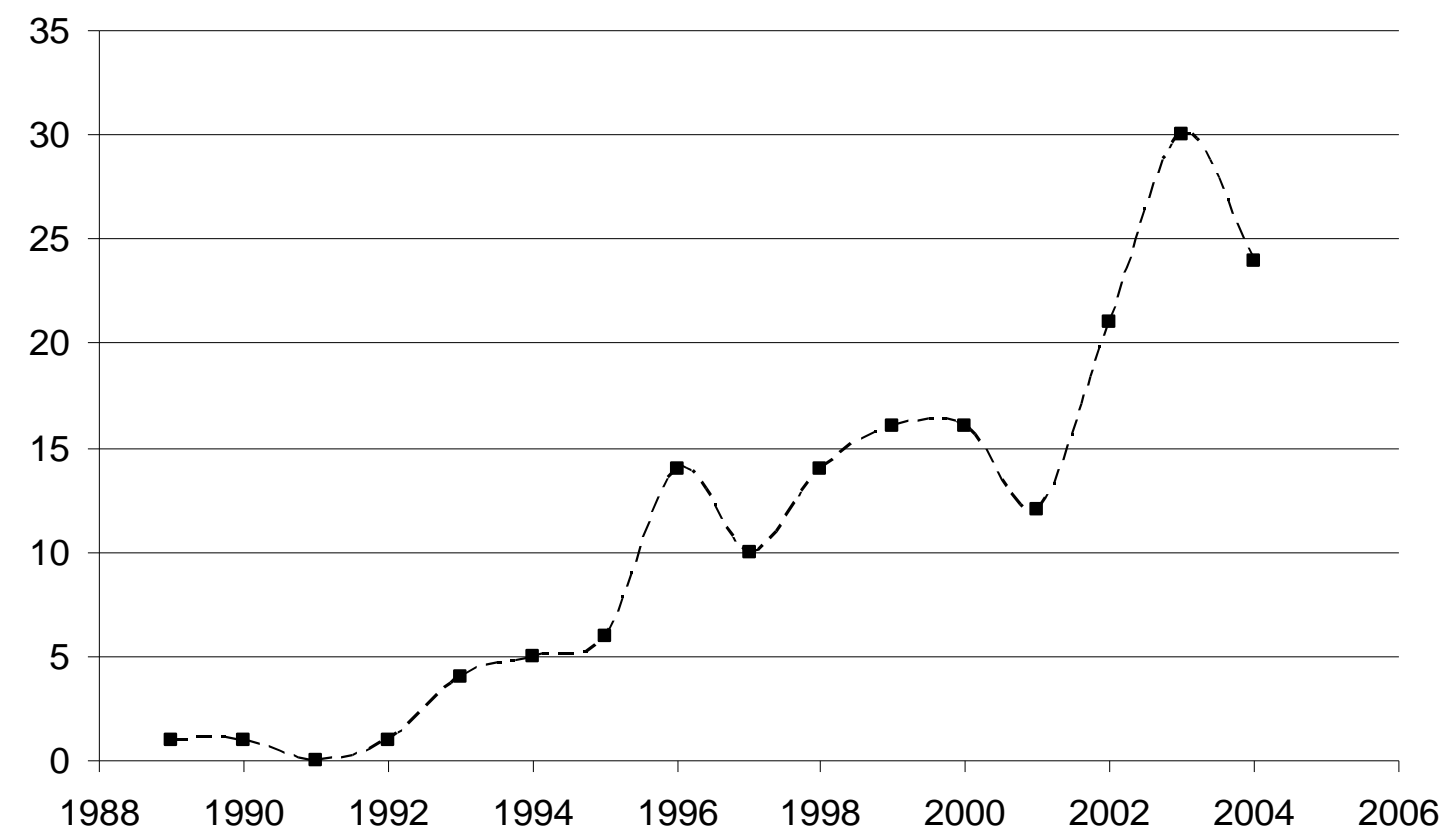

Figure 1: Search results for keyword 'SERVQUAL'

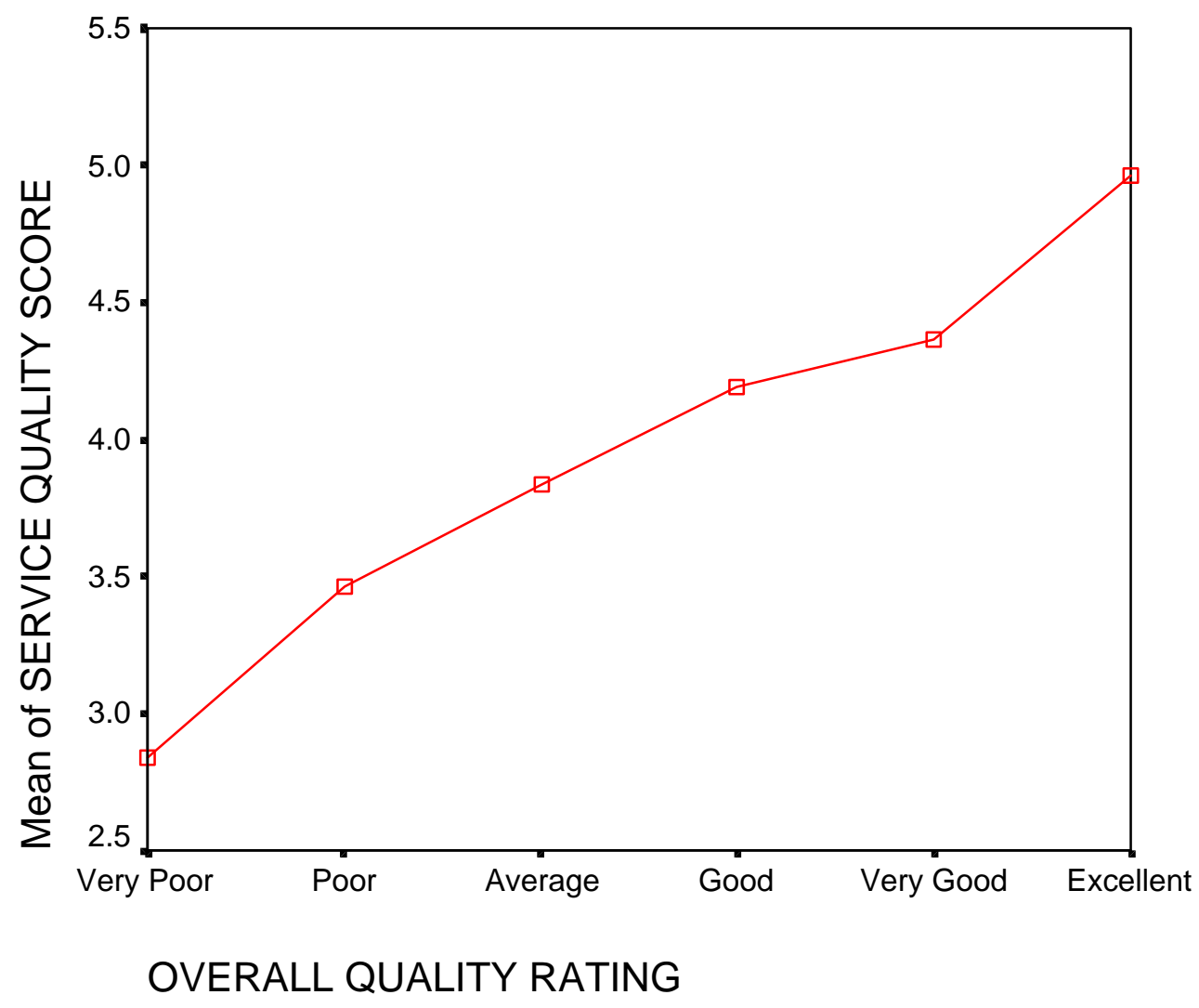

Figure 2: Plot of mean service quality scores for 'overall quality rating' question 